\title{
DQB1*06:02-associated pathogenic anti-myelin autoimmunity in multiple sclerosis-like disease: potential function of DQB1*06:02 as a disease-predisposing allele
}

\section{Nathali Kaushansky* and Avraham Ben-Nun}

Department of Immunology, The Weizmann Institute of Science, Rehovot, Israel

\section{Edited by:}

Amir Sharabi, Tel-Aviv University,

Israel

Reviewed by:

Reinhard Hohlfeld, Ludwig

Maximilians University of Munich,

Germany

Gurumoorthy Krishnamoorthy, Max

Planck Institute of Neurobiology,

Germany

\section{*Correspondence}

Nathali Kaushansky, Department of Immunology, The Weizmann Institute of Science, Rehovot 76100, Israel

e-mail: nathali.kaushansky@

weizmann.ac.il

\begin{abstract}
Susceptibility to multiple sclerosis (MS) has been linked mainly to the HLA-DRB1 locus, with the HLA-DR15 haplotype (DRB1*1501-DQA1*0102-DQB1*0602-DRB5*0101) dominating MS risk in Caucasians. Although genes in the HLA-II region, particularly DRB1*1501, DQA $1{ }^{*} 0102-\mathrm{DQB} 1{ }^{*} 0602$, are in tight linkage disequilibrium, genome-wide-association, and gene candidate studies identified the DRB1*15:01 allele as the primary risk factor in MS. Many genetic and immune-functional studies have indicated DRB1*15:01 as a primary risk factor in MS, while only some functional studies suggested a diseasemodifying role for the DRB5*01 or DQB $1{ }^{*} 06$ alleles. In this respect, the susceptibility of DRB1*15:01-transgenic (Tg) mice to myelin basic protein- or myelin oligodendrocyte glycoprotein-induced MS-like disease is consistent with primary contribution of DRB1*15:01 to HLA-DR15+ MS. The studies summarized here show that susceptibility to MS-like disease, induced in HLA-"humanized" mice by myelin oligodendrocytic basic protein or by the proteolipid protein, one of the most prominent encephalitogenic target antigens implicated in human $M S$, is determined by $D Q B 1{ }^{*} 06: 02$, rather than by the DRB1*15:01 allele. These findings not only offer a rationale for a potential role for DQB $1{ }^{*} 06: 02$ in predisposing susceptibility to $M S$, but also suggest a more complex and differential functional role for HLA-DR15 alleles, depending on the primary target myelin antigen. However, the conflict between these findings in HLA-Tg mice and the extensive genome-wide-association studies, which could not detect any significant effect from the DQB1*06:02 allele on MS risk, is rather puzzling. Functional analysis of MS PBLs for DQB1*06:02-associated anti-myelin autoimmunity may indicate whether or not $\mathrm{DQB} 1{ }^{*} 06: 02$ is associated with MS pathogenesis.
\end{abstract}

Keywords: MS/EAE, antigens/peptides/epitopes, neuroimmunology, T-cells, HLA-DR15-Tg mice

\section{INTRODUCTION}

Multiple sclerosis (MS), the most common neurological disease affecting young adults in the Western world, is a CNS demyelinating disease associated with complex pathogenic autoimmunity against several CNS-myelin target antigens (1). Although the etiology of MS is yet unknown, numerous studies have confirmed a strong genetic component underlying its etiology. Susceptibility to MS has been associated with genes within the major histocompatibility complex have been recognized for several decades, particularly with the genes of the HLA-DR2 serotype (DR15 haplotype) (2). The HLA-DR15 association with MS susceptibility was refined later on, using DNA-based typing methods, to the HLA-DRB1 ${ }^{\star} 1501$ locus (3). More recent genome-wideassociation studies (GWASs), which identified several MHC genes and over 100 non-MHC genetic variants/genes associated with MS

Abbreviations: EAE, experimental autoimmune encephalomyelitis; GWASs, genome-wide-association studies; LD, linkage disequilibrium; MBP, myelin basic protein; MOBP, myelin-associated oligodendrocytic basic protein; MOG, myelin oligodendrocyte glycoprotein; MS, multiple sclerosis; PLP, proteolipid protein; Tg, transgenic mice. susceptibility (4) have localized the greatest effect on MS risk to the HLA-DRB1 locus, with the DRB1*15:01 allele within the HLADR15 haplotype bearing the strongest association with MS. However, the HLA-DR15 haplotype genes (DRB1*15:01, DQA1*01:02, $\mathrm{DQB}^{\star} 06: 02$, and $\left.\mathrm{DRB}^{\star} 01: 01\right)$ are in strong linkage disequilibrium (LD). The remarkable LD between these genes makes it difficult to determine by genetic studies whether the functionally relevant effect on MS derives from $\mathrm{DRB} 1^{\star} 15: 01$ only, or also from its neighboring $\mathrm{DQA1} 1^{\star} 01: 02-\mathrm{DQB} 1^{\star} 06: 02$ or $\mathrm{DRB} 5{ }^{\star} 01: 01$ genes of HLA-DR15 haplotype.

The availability, of "humanized" mice [HLA-transgenic ( $\mathrm{Tg})$ mice] that were genetically manipulated to express either of the human DRB1 ${ }^{\star} 15: 01, \mathrm{DQA}^{\star} 01: 02-\mathrm{DQB1} 1^{\star} 06: 02$, or $\mathrm{DRB} 5{ }^{\star} 01: 01$ molecules, provide a powerful tool to discern the potential contribution of each of these three sets of genes, individually or in combination (epistasis), to the development of MS.

Most previous genetic and immunological studies suggested $\mathrm{DRB1}^{\star} 15: 01$ as the disease-predisposing gene in $\mathrm{MS}(5,6)$ are in agreement with the GWASs, suggesting that greatest risk to MS is driven by the HLA-DRB1 ${ }^{\star}$ 15:01 allele, while association to MS of other alleles of DR15 haplotype is only secondary to their LD with 
HLA-DRB1 ${ }^{\star} 15: 01$ allele $(4,7)$. The HLA-II-Tg mice studies showing that HLA-DRB1 ${ }^{\star} 1501-\mathrm{Tg}$ mice are susceptible to myelin basic protein (MBP)- or myelin oligodendrocyte glycoprotein (MOG)induced experimental autoimmune encephalomyelitis (EAE) (8, 9) are also consistent with the primary contribution of DRB1 ${ }^{\star} 1501$ to MS pathogenesis. However, we recently showed that "humanized" mice expressing DQB1 ${ }^{\star} 06: 02$, but not the $\mathrm{DRB} 1{ }^{\star} 15: 01$, genes can develop MS-like disease mediated by autoimmune cells reactive against a CNS protein, myelin oligodendrocytic basic protein (MOBP) (10), which is also an important target antigen for the immune attack in MS. These findings were the first to implicate $\mathrm{DQB1}{ }^{\star} 06: 02$-associated immune cells in the pathogenesis of MS, and to suggest that $\mathrm{DQB1} 1^{\star} 06: 02$ is also a potential disease-predisposing gene. The $\mathrm{DQB1}{ }^{\star} 06: 02$-associated pathogenic autoimmunity against MOBP target antigen appeared not to be a limited case. We found that the pathogenic autoimmunity against the proteolipid protein (PLP), a highly encephalitogenic target antigen in MS, is also determined by HLA-DQB ${ }^{\star} 06: 02$, and not by HLA-DRB1*15:01 allele $(10,11)$.

Here, we review our and others' studies, which implicate pathogenic DQB1 ${ }^{\star} 06: 02$-associated autoimmunity in the pathogenesis of MS and highlight the possibility that $\mathrm{DQB1}^{\star}{ }^{\star} 06: 02$ is also an important disease-predisposing allele, rather than just disease-modifying as previously perceived (10-14).

\section{HLA-DR15 HAPLOTYPE AND MS}

Multiple sclerosis is associated with complex pathogenic autoimmunity directed against CNS components, with several of the myelin proteins, such as MBP, PLP, MOG, and MOBP, being the major potential target antigens in MS. The genetics of MS is complex; in recent GWASs, several HLA and over 100 non-HLA genes have been associated with the disease, with the DRB1*15:01 within the extended HLA(-DQB $1^{\star} 06: 02,-\mathrm{DQA} 1^{\star} 01: 02,-\mathrm{DRB} 1^{\star} 15: 01$, -DRB5* 01:01) haplotype ("HLA-DR15" haplotype thereafter) bearing the strongest association to MS $(4,15,16)$. Nevertheless, extensive LD among these loci, makes it difficult not unequivocally establish by fine-genetic mapping studies whether the functionally relevant effect on MS derives from $\mathrm{DRB}^{\star}{ }^{\star} 15: 01, \mathrm{DQA} 1^{\star} 01: 02$, $\mathrm{DQB}^{\star} 06: 02$, or $\mathrm{DRB}^{\star} 01: 01$ loci of HLA-DR15, their combination, or from their epistatic interactions. Although many previous genetic studies indicated $\mathrm{DRB}^{\star} 15: 01$ as the primary risk factor in MS among the Caucasian populations $(5,17,18)$, studies with unique populations show selective association with $\mathrm{DRB}^{\star}$ 15:01 independent of $\mathrm{DQB} 1^{\star}$ 06:02 [African-Americans (19)]. In African-Brazilian MS patients, the association was with HLA-DQB1 ${ }^{\star} 06: 02$ rather than HLA-DRB1 $^{\star}$ 15:01 (13). More recent studies showed that individuals with incomplete haplotypes bearing only HLA-DRB1 ${ }^{\star} 15: 01$ or $\mathrm{HLA}-\mathrm{DQB} 1^{\star} 06: 02$ were not predisposed to MS; the HLA-DQA ${ }^{\star} 01: 02$, which by itself shows no primary association with MS, increases the risk of MS when combined with HLA-DRB1*15:01 in trans, and plays a protective role in the absence of HLA-DRB ${ }^{\star} 15: 01$ (20). This study also suggested that all three HLA-DRB1, HLA-DQA1, and HLA-DQB1 alleles can affect MS susceptibility through epistatic interactions (20). In addition to HLA-DRB1 ${ }^{\star} 15: 01$, there are other HLA-DRB1 alleles that can also increase MS risk [such as HLA-DRB1*17:03 allele in the Swedish and Canadian MS populations (21)], albeit to a lesser extent, while other HLA-DRB1 alleles, particularly HLA$\mathrm{DRB}^{\star} 14$ can abrogate the risk associated with HLA-DRB1* 15 when they are inherited together (22), apparently via functional epistasis. Thus, the effect of the MHC on susceptibility to MS appears quite complex as it may involve also complex interactions between alleles of HLA haplotypes through cis or trans functional epistatic interactions, suggesting the significance of haplotypic rather than allelic association between HLA and MS. Yet, the HLA-DR15 haplotype, comprising the $\mathrm{DRB} 1^{\star} 15: 01$, DQA $1^{\star} 01: 02$, $\mathrm{DQB1}^{\star} 06: 02$, and $\mathrm{DRB}^{\star} 01: 01$ alleles, is the most prevalent haplotype $(\sim 30 \%)$ among MS patients of the Western population.

\section{HLA-D0B1*06:02 ALLELE IN UNIOUE POPULATIONS WITH MS}

While most MS genetics studies in North European, Caucasian populations suggest the HLA-DRB $1^{\star} 15: 01$ as the genetic risk factor in MS (5), Spurkland, Thorsby, and Vartdal studied the specific HLA-DR and DQ alleles of 181 Norwegian MS patients. Patients who carried DQB1 ${ }^{\star} 06: 02$ or $06: 03$ without $\mathrm{DRB} 1^{\star} 15: 01$ were identified, but none who were $\mathrm{DRB1}{ }^{\star} 15: 01$ without $\mathrm{DQB1} 1^{\star} 06: 02(23)$ were identified. Related observations were made in a relatively small cohort of Hong Kong Chinese patients with MS. In this specific Chinese patients, DR15 is expressed without DQB1 ${ }^{\star} 06: 02$ and DQB $1^{\star} 06: 02$ without DR15, so that one can ask whether either or both of the dissociated genes appear to confer an enhanced risk. It was found that the enhanced risk to MS was associated with DQB1 ${ }^{\star} 06: 02$ (12). A similar case has been made for MS susceptibility in Afro-Brazilians, where the frequency of $\mathrm{DQB}{ }^{\star} 06: 02$ among patients is higher than for the main DR15 allele in that unique population, DRB1*15:03 (13). Hence, in African populations that show greater haplotypic diversity than European and also distinct patterns of $\mathrm{LD}$, it was possible to separately appraise the relative contributions of HLA-DR and DQ sequences to susceptibility. A caveat here is the analysis of HLA-DR and DQ associations conducted in a large cohort of African American MS patients, where a selective association with HLA-DRB $1^{\star} 15: 01$ and not with HLADQB1 ${ }^{\star} 06: 02$ was identified (19). Another study in MS patients from Malaga, Spain, that showed association of HLA-DQB ${ }^{\star} 06: 02$ with MS in the absence of DRB1*15:01 (14) is in line with the findings in the African Brazilians. These studies suggest that HLA DRB1*15:01 may not be the sole determinant of MS susceptibility.

\section{MYELIN T-CELL EPITOPES IN HLA-Tg MICE}

Immunodominant epitopes in MS are also often encephalitogenic epitopes in relevant susceptible experimental animals [e.g., MBP 89-101 in SJL/J mice (24), PLP 43-64 in Pl/J mice (25), MOG 35-55 in $\mathrm{H}-2^{\mathrm{b}}$ mice $(26,27)$, Lewis rats $(28)$ and Rhesus monkeys (29), and MOBP 65-86 in $\mathrm{H}-2^{\mathrm{b}}$ mice (30)]. Nevertheless, these animal models do not fully reflect the immune responses seen in MS. In this regard, HLA-Tg mice are a more powerful tool for the analysis of human T-cell responses to myelin epitopes, their association with particular HLA-restriction elements, and their pathogenic credentials. Proof of principle that human T-cell responses can be studied in the "humanized" HLA-Tg mouse model was provided by the demonstration of T-cell responses to MBP 139-154 in HLA-DR Tg mice (8) and the induction of EAE with MBP 84102 in HLA-DR2-transgenic mice, which also express a human TCR recognizing the MBP epitope (31). 
In the study of Sireci et al., MBP13-33, 139-154, and 87106 , reported as being presented by different HLA class II alleles, were tested for their ability to induce HLA restricted proliferative responses in HLA-DR1 Tg mice (32). Of these, only MBP13-33 induced severe EAE in the HLA-DR1 Tg mice (32); MBP87-106, which is an immunodominant MBP epitope in MS, induced only weak responses and very mild EAE (32). A more comprehensive study in HLA-Tg of the HLA-restriction of MBP epitopes was conducted by Das et al. (33). In their study, the reactivity to overlapping peptides spanning the MBP molecule by cells isolated from myelin-primed mice singly transgenic for HLA-DR3, -DQ6, or -DQ8, or double transgenic for HLA-DR3/DQ6 or -DR3/DQ8, was investigated, and a strong T-cell response to MBP81-100 was observed in HLA-DR3/DQ8 Tg mice resulting in severe EAE (33).

Reports on the association of PLP epitopes with specific HLA alleles in HLA-Tg mice are scarce. PLP175-192 considered as immunodominant in HLA-DR4 individuals could induce a strong response accompanied with clinical symptoms of EAE in HLADR4-IE Tg mice (34); T-cell lines to the HLA-DR2 MS-associated PLP95-116 that were raised from HLA-DR2 Tg mice could induce neurological impairment upon transfer into these mice $(10,35)$. More recently, TCR ${ }^{\mathrm{PLP} 45-53} \mathrm{Tg}$ mice were generated and were used

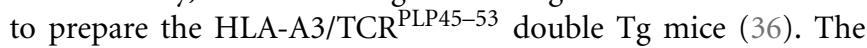
most comprehensive studies in HLA-Tg mice have been conducted to identify the immunodominant epitopes of $\operatorname{MOG}(37,38)$. In the study of Khare et al. (38), HLA-Tg (-DR2, -DR3, -DR4, -DQ6-601, -DQ6-604, and -DQ8) mice were immunized with recombinant MOG (rMOG) and the primed lymph node cells tested for reactivity to overlapping peptides. All six transgenics showed strong responses to MOG1-20, 31-50, and 61-80, which were shown as immunodominant epitopes in MS (39). HLA-DR2 Tg mice also reacted to MOG 91-110, which is immunodominant in the T-cell response to MOG in rhesus monkeys with MOG-induced EAE (29); HLA-DR4 Tg mice reacted to MOG31-50 and 91-110 and the potential relevance of this latter epitope to MS pathogenesis was confirmed by the study of Forsthuber et al. (37). They showed that HLA-DR4 Tg mice immunized with rMOG respond predominantly to MOG 97-108 and develop severe EAE (37). Another example of clinical EAE in HLA-Tg mice is the study reporting MOG35-55-induced EAE in HLA-DR2 Tg mice (9).

Various examples of TCR transgenics expressing MS patientderived TCRs $(31,36,40)$, or expressing murine TCR-Tg of pathogenic T-cells $(41,42)$ have been described. Several new observations were made in humanized TCR models, progressing translational, and understanding of MS T-cell responses beyond the generic observations that have been made with standard murine EAE models. The humanized transgenic models provide information that could not be obtained using assays of patientderived cells, e.g., pathogenic credentials of autoimmune response to myelin epitopes. For many years, studies have defined patterns of autoimmune anti-myelin T-cell responses of MS patients. Some myelin epitopes were identified to be more disease specific than others, and some were more clearly related to disease progression than others. However, as the responses in MS are assessed in ex vivo cultures, it has not been possible to attribute functional, pathogenic outcomes to these responses. For this purpose, HLA-Tg mice genetically manipulated to express TCRs specific to myelin epitope(s) that develop spontaneous MS-like disease are instrumental.

Strikingly, none of the reported humanized TCR transgenics express TCR specific for an HLA-DQ6-restricted myelin epitopes. Furthermore, and quite surprisingly, extensively reviewing the literature on studies devoted to defining MS-relevant myelin epitopes in humans (MS) revealed that little importance was given to DQ6-presented epitopes, as the vast majority of studies reported only DR15-associated epitopes. A similar situation was noticed in the studies on humanized HLA-Tg mice. Only one group $(38,43)$ studied EAE in HLA-DQ6-Tg mice, and analyzed epistatic effects between DQ6 and DR alleles on PLP-induced EAE, although none of the DQ and DR alleles in these studies $(32,33,43,44)$ were of the HLA-DR15 haplotype, the most prevalent haplotype in MS. Thus, it appears that the HLA-DQ6-associated autoimmune reactivity against CNS antigens has only been poorly explored, particularly the autoimmunity associated with DQB1*06:02 molecule of the HLA-DR15 haplotype. The reasons are not clear, and are even less understood, as DQ6-associated anti-myelin autoreactivity may also play a role in the pathogenesis of MS, as suggested from studies in some unique populations (12-14) or from our study showing that $\mathrm{DQB} 1^{\star} 06: 02$, but not $\mathrm{DRB} 1^{\star} 15: 01$, determine disease susceptibility to MOBP or PLP in HLA-Tg mice $(10,11)$.

\section{HLA-DQB1*06:02-ASSOCIATED SUSCEPTIBILITY TO MS-LIKE DISEASE INDUCED BY HUMAN MOBP IN HLA-TRANSGENICS} MOBP is a CNS-myelin-specific protein that plays a role in stabilizing the myelin sheath (45). Northern blot analysis, in situ hybridization, immunochemistry, and immunoelectron microscopy $(45,46)$ indicated that MOBP is expressed exclusively in CNS white matter, and more particularly throughout compact myelin, predominantly at the major dense lines of myelin (45). The encephalitogenic potential of MOBP was demonstrated in $\mathrm{H}-2^{\mathrm{b}}$ mice with the MOBP65-88 being the encephalitogenic epitope (30), and in the H-2 (47) mice with MOBP15-36 epitope being the immunodominant and encephalitogenic epitope. The relevance of the autoimmunity against these encephalitogenic epitopes to the pathogenesis of MS was investigated by analyzing the autoreactivity to overlapping human MOBP peptides by MS patients and healthy control individuals. In two separate studies $(30,47)$, analysis of the proliferative response to MOBP peptides by PBLs from MS patients and controls revealed autoreactivity to MOBP1-23, MOBP15-36, and MOBP65-87 epitopes in MS patients and controls. Although a significant difference between MS patients and controls could not be determined, two of the epitopes that were detected by the PBLs, MOBP15-36 and MOBP65-87, were found encephalitogenic for mice, suggesting the relevance of autoimmunity against MOBP15-36 and MOBP65-87 epitopes to MS pathogenesis $(30,47)$. In another study, Holz et al. (48) showed proliferative response to several human MOBP epitopes by PBLs from relapsing/remitting MS patients and controls, with reactivity to MOBP21-39 somewhat higher in MS patients (48).

We used HLA-Tg mice expressing either the $\mathrm{DRB1}{ }^{\star} 15: 01$ or DQB1 ${ }^{\star} 06: 02$ heterodimers, as well as $\left(\mathrm{DRB} 1^{\star} 15: 01 \times \mathrm{DQB} 1^{\star} 06\right.$ : 02)F1 double Tg mice (10), in order to illuminate the relative 
potential contribution of each of these molecules, or their co-expression, to MOBP-associated pathogenic autoimmunity in MS patients with the "HLA-DR15 haplotype." We showed (10) that while the HLA-DRB1 ${ }^{\star} 15: 01$ transgenics are refractory to disease induction, the HLA-DQB1*06:02 Tg mice are susceptible to EAE induction by hMOBP, through pathogenic Tcells reactive against MOBP15-36 and MOBP55-77 encephalitogenic epitopes. $\mathrm{HLA}\left(\mathrm{DRB} 1^{\star} 15: 01 \times \mathrm{DQB} 1^{\star} 06: 02\right) \mathrm{F} 1$ double $\mathrm{Tg}$ mice were also susceptible to EAE induction by hMOBP, although the $\mathrm{DRB} 1^{\star} 15: 01 / \mathrm{MOBP} 15-36$ reactive $\mathrm{T}$-cells are antiinflammatory. The presence of the HLA-DRB1 ${ }^{\star} 15: 01$ gene product in the HLA- $\left(\mathrm{DRB} 1^{\star} 15: 01 \times \mathrm{DQB} 1^{\star} 06: 02\right) \mathrm{F} 1$ double Tg mice did not impose any immunomodulatory effect. The pathology was essentially similar between HLA-DQB1 ${ }^{\star} 06: 02$ and HLA $\left(\mathrm{DRB1}{ }^{\star}\right.$ 15:01 $\times \mathrm{DQB1}^{\star}$ 06:02) F1 double Tg mice, and pathological manifestations were highly reminiscent of MS. Both immunogenic peptides (MOBP15-36 and MOBP55-77) caused overt clinical EAE associated with perivascular and parenchymal infiltrates, widespread demyelination, axonal loss, and optic neuritis with a high degree of demyelination in the optic nerve (10). This study, which presented a new "humanized" model of MS-like disease provided the first evidence of pathogenic HLA-DQ-associated antimyelin autoimmunity, and further implicated the autoimmunity against MOBP in the pathogenesis of MS (10).

\section{HLA-DQB1*06:02 DETERMINES SUSCEPTIBILITY TO MS-LIKE} DISEASE INDUCED BY PLP IN HLA-DR15 TRANSGENIC MICE While our recent study (10) showing that MOBP can induce MSlike disease in HLA-DQB1 ${ }^{\star} 06: 02-\mathrm{Tg}$ mice offers a rationale for the HLA-DQB1 ${ }^{\star} 06: 02$ association with MS, it raised the question of whether DQ6-autoimmunity against other myelin/neuronal target antigens/epitopes can be pathogenic and may also play a role in pathogenesis of MS. PLP autoimmunity has been strongly implicated in MS. Some functional studies have also attempted to correlate immune reactivity with MS relapse (49). We therefore investigated the pathogenic potential of PLP in HLA-Tg mice expressing the $\mathrm{DRB} 1^{\star} 15: 01$ and $\mathrm{DQB} 1^{\star} 06: 02$ gene products of the HLA-DR15 haplotype. Our results (11) showed that the DQB ${ }^{\star} 06: 02$-associated pathogenic autoimmunity against MOBP is not a limited case, and that $\mathrm{DQB} 1^{\star} 06: 02$-autoimmunity against other CNS antigens may also play a role in the pathogenesis of MS. We showed that susceptibility to a "humanized" MS-like disease induced by highly encephalitogenic protein, PLP, which is the most abundant CNS protein and one of the most prominent target antigens implicated in human $\mathrm{MS}$, is determined by HLA-DQB1 ${ }^{\star} 06: 02$, and not by $\mathrm{DRB} 1^{\star} 15: 01$. Thus, the HLA$\mathrm{DRB}^{\star}{ }^{\star}$ 15:01 transgenics were found to be refractory to PLP disease induction, whereas the HLA-DQB $1^{\star} 06: 02$ transgenics were susceptible via T-cells reactive against PLP139-151 and PLP175-194 encephalitogenic epitopes. Although both transgenics react against these epitopes, the PLP139-151 and PLP175-194-reactive T-cells are of Th2-type in HLA-DRB1 ${ }^{\star} 15: 01$ transgenics, and pathogenic Th1/Th17-type cells in the HLA-DQB1*06:02 transgenic mice. The PLP-induced EAE in HLA-DQB ${ }^{\star} 06: 02$ transgenic mice showed a typical caudo-rostral clinical progression that was associated with CNS demyelination, axonal damage, and with optic neuritis. However, unlike usually observed in PLP-induced disease or other EAE models in the wild type mice, the CNS pathology in phPLP175-194-induced EAE in HLA-DQB1 ${ }^{\star} 06: 02$ transgenics was more pronounced in the brain rather than in the spinal cord (11). Such a strong involvement of cerebellum and brainstem exceeding that of spinal cord, which has been suggested by Stromnes et al. (50) to be a feature of Th17-driven disease, corresponded to the high Th17 secretion by PLP175-194-primed LNC derived from $\mathrm{DQB1}{ }^{\star} 06: 02-\mathrm{Tg}$ mice.

\section{SUMMARY}

HLA-DR15-Tg mice are instrumental in investigating the encephalitogenic potential of myelin/neuronal epitopes relevant to HLA-DR15+ MS in the context of the genes encoding the individual molecules comprising the HLA-DR15 haplotype. While the previously reported susceptibility of $\mathrm{DRB} 1^{\star} 15: 01-\mathrm{Tg}$ mice to MBP- or MOG-induced EAE is consistent with the primary contribution of $\mathrm{DRB} 1^{\star} 15: 01$ to MS pathogenesis, our recent studies in HLA-Tg mice showed that DQB1 ${ }^{\star} 06: 02$ but not $\mathrm{DRB} 1^{\star} 15: 01$ determines pathogenic autoimmunity against PLP as well as against $\operatorname{MOBP}(10,11)$. These findings provide a rationale, and mechanisms, for the involvement of HLA-DQB1 ${ }^{\star} 06: 02$-associated pathogenic autoimmunity in the pathogenesis of MS, thereby, implicating the HLA-DQB1 ${ }^{\star} 06: 02$ in the genetic susceptibility to MS. This places MS more firmly in the group of autoimmune diseases in which a functional association is presumed, including type I diabetes and celiac disease $(40,51)$. The findings showing that DQB1 ${ }^{\star}$ 06:02 determines pathogenic autoimmunity against PLP (11) and MOBP (10) together with previously reported studies showing that $\mathrm{DRB}{ }^{\star} 15: 01$ determines pathogenic autoimmunity against MBP and MOG $(8,9)$ suggest a more complex and differential genetic predisposition to HLA-DR15+ MS, depending on the primary CNS target antigen/epitope against which the pathogenic autoimmunity is primarily directed (or triggered). It is quite puzzling, however, that the pathogenic DQB1*06:02-associated anti-myelin autoimmunity that emerged from functional studies in HLA-Tg mice is not reflected by the extensive GWASs in MS, which determined the $\mathrm{DRB} 1^{\star} 15: 01$ as the major risk allele in MS without any significant association of $\mathrm{DQB} 1^{\star} 06: 02$ with MS risk. Whether the pathogenic DQB1 ${ }^{\star} 06: 02$-associated autoimmunity is limited to the reductionist transgenic models of MS, or whether GWASs could not distinguish the DQA1 ${ }^{\star} 01: 02$ and $\mathrm{DQB} 1^{\star} 06: 02$-related functionally relevant effects on MS risk from the functional effects driven by $\mathrm{DRB1}{ }^{\star} 15: 01$ allele, due to strong LD, would require functional studies with PBLs of HLADR15 ${ }^{+}$MS patients, in particular PBLs reactive against MOBP and/or PLP.

\section{TAKE HOME MESSAGES}

- The susceptibility to MS-like disease induced by MBP or MOG in HLA-Tg mice is determined by $\mathrm{DRB} 1^{\star} 15: 01$, while disease induced by MOBP or PLP is controlled by DQB1*06:02.

- These findings have important bearing on the candidacy of the DQB1 ${ }^{\star}$ 06:02 allele as genetic risk factor for MS.

- These findings in transgenic models also suggest a more complex and differential functional role for HLA-DR15 genes in determining susceptibility to MS, depending on the target brain-myelin antigen. 


\section{ACKNOWLEDGMENTS}

This work was supported in part by the Israel Science Foundation, National Multiple Sclerosis Society of New York Grant RG 3195B8/2, the Israel Ministry of Health, the Estate of the Late Florence Blau, the William Sahm Foundation, the Adiel Eleanor foundation, and by the Nella and Leon Benoziyo Center for Neurological Diseases. Avraham Ben-Nun is the incumbent of the Eugeneand Marcia Applebaum Professorial Chair.

\section{REFERENCES}

1. Sospedra M, Martin R. Immunology of multiple sclerosis. Annu Rev Immunol (2005) 23:683-747. doi:10.1146/annurev.immunol.23.021704.115707

2. Compston DA, Batchelor JR, McDonald WI. B-lymphocyte alloantigens associated with multiple sclerosis. Lancet (1976) 2(7998):1261-5. doi:10.1016/S01406736(76)92027-4

3. Olerup O, Hillert J. HLA class II-associated genetic susceptibility in multiple sclerosis: a critical evaluation. Tissue Antigens (1991) 38(1):1-15. doi:10.1111/j. 1399-0039.1991.tb02029.x

4. International Multiple Sclerosis Genetics C, Beecham AH, Patsopoulos NA, Xifara DK, Davis MF, Kemppinen A, et al. Analysis of immune-related loci identifies 48 new susceptibility variants for multiple sclerosis. Nat Genet (2013) 45(11):1353-60. doi:10.1038/ng.2770

5. Hauser SL, Oksenberg JR. The neurobiology of multiple sclerosis: genes, inflammation, and neurodegeneration. Neuron (2006) 52(1):61-76. doi:10.1016/j. neuron.2006.09.011

6. Barcellos LF, Sawcer S, Ramsay PP, Baranzini SE, Thomson G, Briggs F, et al. Heterogeneity at the HLA-DRB1 locus and risk for multiple sclerosis. Hum Mol Genet (2006) 15(18):2813-24. doi:10.1093/hmg/ddl223

7. Patsopoulos NA, Barcellos LF, Hintzen RQ, Schaefer C, van Duijn CM, Noble JA, et al. Fine-mapping the genetic association of the major histocompatibility complex in multiple sclerosis: HLA and non-HLA effects. PLoS Genet (2013) 9(11):e1003926. doi:10.1371/journal.pgen.1003926

8. Altmann DM, Douek DC, Frater AJ, Hetherington CM, Inoko H, Elliott JI. The $\mathrm{T}$ cell response of HLA-DR transgenic mice to human myelin basic protein and other antigens in the presence and absence of human CD4. J Exp Med (1995) 181(3):867-75. doi:10.1084/jem.181.3.867

9. Rich C, Link JM, Zamora A, Jacobsen H, Meza-Romero R, Offner H, et al. Myelin oligodendrocyte glycoprotein-35-55 peptide induces severe chronic experimental autoimmune encephalomyelitis in HLA-DR2-transgenic mice. Eur J Immunol (2004) 34(5):1251-61. doi:10.1002/eji.200324354

10. Kaushansky N, Altmann DM, Ascough S, David CS, Lassmann H, Ben-Nun A. HLA-DQB1 ${ }^{\star} 0602$ determines disease susceptibility in a new "humanized" multiple sclerosis model in HLA-DR15 $\left(\mathrm{DRB}^{\star} 1501\right.$;DQB1 $\left.{ }^{\star} 0602\right)$ transgenic mice. J Immunol (2009) 183(5):3531-41. doi:10.4049/jimmunol.0900784

11. Kaushansky N, Altmann DM, David CS, Lassmann H, Ben-Nun A. DQB1 ${ }^{\star} 0602$ rather than $\mathrm{DRB} 1^{\star} 1501$ confers susceptibility to multiple sclerosis-like disease induced by proteolipid protein (PLP). J Neuroinflammation (2012) 9:29-43. doi:10.1186/1742-2094-9-29

12. Serjeantson SW, Gao X, Hawkins BR, Higgins DA, Yu YL. Novel HLA-DR2related haplotypes in Hong Kong Chinese implicate the DQB1*0602 allele in susceptibility to multiple sclerosis. Eur J Immunogenet (1992) 19(1-2):11-9. doi:10.1111/j.1744-313X.1992.tb00043.x

13. Alves-Leon SV, Papais-Alvarenga R, Magalhaes M, Alvarenga M, Thuler LC. Fernandez y Fernandez O: ethnicity-dependent association of HLA DRB1-DQA1DQB1 alleles in Brazilian multiple sclerosis patients. Acta Neurol Scand (2007) 115(5):306-11. doi:10.1111/j.1600-0404.2006.00750.x

14. Fernandez O, Fernandez V, Alonso A, Caballero A, Luque G, Bravo M, et al. DQB1 ${ }^{\star} 0602$ allele shows a strong association with multiple sclerosis in patients in Malaga, Spain. J Neurol (2004) 251(4):440-4. doi:10.1007/s00415004-0350-2

15. Oksenberg JR, Baranzini SE, Sawcer S, Hauser SL. The genetics of multiple sclerosis: SNPs to pathways to pathogenesis. Nat Rev Genet (2008) 9(7):516-26. doi:10.1038/nrg2395

16. McElroy JP, Oksenberg JR. Multiple sclerosis genetics. Neurol Clin (2010) 29(2):219-31. doi:10.1016/j.ncl.2010.12.002

17. Sawcer S, Hellenthal G, Pirinen M, Spencer CC, Patsopoulos NA, Moutsianas L, et al. Genetic risk and a primary role for cell-mediated immune mechanisms in multiple sclerosis. Nature (2011) 476(7359):214-9. doi:10.1038/ nature10251

18. Oksenberg JR, Baranzini SE. Multiple sclerosis genetics - is the glass half full, or half empty? Nat Rev Neurol (2010) 6(8):429-37. doi:10.1038/nrneurol.2010.91

19. Oksenberg JR, Barcellos LF, Cree BA, Baranzini SE, Bugawan TL, Khan O, et al. Mapping multiple sclerosis susceptibility to the HLA-DR locus in African Americans. Am J Hum Genet (2004) 74(1):160-7. doi:10.1086/380997

20. Lincoln MR, Ramagopalan SV, Chao MJ, Herrera BM, Deluca GC, Orton SM, et al. Epistasis among HLA-DRB1, HLA-DQA1, and HLA-DQB1 loci determines multiple sclerosis susceptibility. Proc Natl Acad Sci U S A (2009) 106(18):7542-7. doi:10.1073/pnas.0812664106

21. Masterman T, Ligers A, Olsson T, Andersson M, Olerup O, Hillert J. HLADR15 is associated with lower age at onset in multiple sclerosis. Ann Neurol (2000) 48(2):211-9. doi:10.1002/1531-8249(200008)48:2<211::AID-ANA11> 3.0.CO;2-R

22. Ramagopalan SV, Morris AP, Dyment DA, Herrera BM, DeLuca GC, Lincoln $\mathrm{MR}$, et al. The inheritance of resistance alleles in multiple sclerosis. PLoS Genet (2007) 3(9):1607-13. doi:10.1371/journal.pgen.0030150

23. Spurkland A, Celius EG, Knutsen I, Beiske A, Thorsby E, Vartdal F. The HLADQ(alpha $1^{\star} 0102$, beta $1^{\star} 0602$ ) heterodimer may confer susceptibility to multiple sclerosis in the absence of the HLA-DR(alpha $1^{\star} 01$, beta $1^{\star} 1501$ ) heterodimer. Tissue Antigens (1997) 50(1):15-22. doi:10.1111/j.1399-0039.1997. tb02828.x

24. Sakai K, Sinha AA, Mitchell DJ, Zamvil SS, Rothbard JB, McDevitt HO, et al. Involvement of distinct murine T-cell receptors in the autoimmune encephalitogenic response to nested epitopes of myelin basic protein. Proc Natl Acad Sci US A (1988) 85(22):8608-12. doi:10.1073/pnas.85.22.8608

25. Whitham RH, Jones RE, Hashim GA, Hoy CM, Wang RY, Vandenbark AA, et al. Location of a new encephalitogenic epitope (residues 43 to 64) in proteolipid protein that induces relapsing experimental autoimmune encephalomyelitis in PL/J and (SJL x PL)F1 mice. J Immunol (1991) 147(11):3803-8.

26. Kerlero de Rosbo N, Mendel I, Ben-Nun A. Chronic relapsing experimental autoimmune encephalomyelitis with a delayed onset and an atypical clinical course, induced in PL/J mice by myelin oligodendrocyte glycoprotein (MOG)derived peptide: preliminary analysis of MOG T cell epitopes. Eur J Immunol (1995) 25(4):985-93. doi:10.1002/eji.1830250419

27. Mendel Kerlero de Rosbo N, Ben-Nun A. Delineation of the minimal encephalitogenic epitope within the immunodominant region of myelin oligodendrocyte glycoprotein: diverse $\mathrm{V}$ beta gene usage by $\mathrm{T}$ cells recognizing the core epitope encephalitogenic for $\mathrm{T}$ cell receptor $\mathrm{V}$ beta $\mathrm{b}$ and $\mathrm{T}$ cell receptor $\mathrm{V}$ beta $\mathrm{a} \mathrm{H}-2 \mathrm{~b}$ mice. Eur J Immunol (1996) 26(10):2470-9.

28. Johns TG, Kerlero de Rosbo N, Menon KK, Abo S, Gonzales MF, Bernard CC. Myelin oligodendrocyte glycoprotein induces a demyelinating encephalomyelitis resembling multiple sclerosis. J Immunol (1995) 154(10):5536-41.

29. Kerlero de Rosbo N, Brok HP, Bauer J, Kaye JF, Hart BA, Ben-Nun A. Rhesus monkeys are highly susceptible to experimental autoimmune encephalomyelitis induced by myelin oligodendrocyte glycoprotein: characterisation of immunodominant T- and B-cell epitopes. J Neuroimmunol (2000) 110(1-2):83-96. doi:10.1016/S0165-5728(00)00306-4

30. Kaye JF, Kerlero de Rosbo N, Mendel I, Flechter S, Hoffman M, Yust I, et al. The central nervous system-specific myelin oligodendrocytic basic protein (MOBP) is encephalitogenic and a potential target antigen in multiple sclerosis (MS). J Neuroimmunol (2000) 102(2):189-98. doi:10.1016/S0165-5728(99) 00168-X

31. Madsen LS, Andersson EC, Jansson L, Krogsgaard M, Andersen CB, Engberg J, et al. A humanized model for multiple sclerosis using HLA-DR2 and a human T-cell receptor. Nat Genet (1999) 23(3):343-7. doi:10.1038/15525

32. Sireci G, Dieli F, Caccamo N, Barera A, Carta P, Di Sano C, et al. A human leucocyte antigen-DR1 transgene confers susceptibility to experimental allergic encephalomyelitis elicited by an epitope of myelin basic protein. Scand J Immunol (2003) 58(2):188-94. doi:10.1046/j.1365-3083.2003.01296.x

33. Das P, Drescher KM, Geluk A, Bradley DS, Rodriguez M, David CS. Complementation between specific HLA-DR and HLA-DQ genes in transgenic mice determines susceptibility to experimental autoimmune encephalomyelitis. Hum Immunol (2000) 61(3):279-89. doi:10.1016/S0198-8859(99)00135-4

34. Ito K, Bian HJ, Molina M, Han J, Magram J, Saar E, et al. HLA-DR4-IE chimeric class II transgenic, murine class II-deficient mice are susceptible to experimental allergic encephalomyelitis. J Exp Med (1996) 183(6):2635-44. doi:10.1084/jem.183.6.2635 
35. Kawamura K, Yamamura T, Yokoyama K, Chui DH, Fukui Y, Sasazuki T, et al. Hla-DR2-restricted responses to proteolipid protein 95-116 peptide cause autoimmune encephalitis in transgenic mice. JClin Invest (2000) 105(7):977-84. doi:10.1172/JCI8407

36. Friese MA, Jakobsen KB, Friis L, Etzensperger R, Craner MJ, McMahon RM, et al. Opposing effects of HLA class I molecules in tuning autoreactive CD8+ T cells in multiple sclerosis. Nat Med (2008) 14(11):1227-35. doi:10.1038/nm. 1881

37. Forsthuber TG, Shive CL, Wienhold W, de Graaf K, Spack EG, Sublett R, et al. T cell epitopes of human myelin oligodendrocyte glycoprotein identified in HLADR4 (DRB1 $\left.{ }^{\star} 0401\right)$ transgenic mice are encephalitogenic and are presented by human B cells. J Immunol (2001) 167(12):7119-25. doi:10.4049/jimmunol.167. 12.7119

38. Khare M, Rodriguez M, David CS. HLA class II transgenic mice authenticate restriction of myelin oligodendrocyte glycoprotein-specific immune response implicated in multiple sclerosis pathogenesis. Int Immunol (2003) 15(4):535-46. doi:10.1093/intimm/dxg053

39. Kerlero de Rosbo N, Hoffman M, Mendel I, Yust I, Kaye J, Bakimer R, et al. Predominance of the autoimmune response to myelin oligodendrocyte glycoprotein (MOG) in multiple sclerosis: reactivity to the extracellular domain of MOG is directed against three main regions. Eur J Immunol (1997) 27(11):3059-69. doi:10.1002/eji.1830271144

40. Erlich H, Valdes AM, Noble J, Carlson JA, Varney M, Concannon P, et al. HLA DR-DQ haplotypes and genotypes and type 1 diabetes risk: analysis of the type 1 diabetes genetics consortium families. Diabetes (2008) 57(4):1084-92. doi:10.2337/db07-1331

41. Pollinger B, Krishnamoorthy G, Berer K, Lassmann H, Bosl MR, Dunn R, et al. Spontaneous relapsing-remitting EAE in the SJL/J mouse: MOG-reactive transgenic T cells recruit endogenous MOG-specific B cells. J Exp Med (2009) 206(6):1303-16. doi:10.1084/jem.20090299

42. Bettelli E, Pagany M, Weiner HL, Linington C, Sobel RA, Kuchroo VK. Myelin oligodendrocyte glycoprotein-specific T cell receptor transgenic mice develop spontaneous autoimmune optic neuritis. J Exp Med (2003) 197(9):1073-81. doi: $10.1084 /$ jem. 20021603

43. Khare M, Mangalam A, Rodriguez M, David CS. HLA DR and DQ interaction in myelin oligodendrocyte glycoprotein-induced experimental autoimmune encephalomyelitis in HLA class II transgenic mice. J Neuroimmunol (2005) 169(1-2):1-12. doi:10.1016/j.jneuroim.2005.07.023

44. Mangalam A, Luckey D, Basal E, Jackson M, Smart M, Rodriguez M, et al. HLA-DQ8 (DQB1*0302)-restricted Th17 cells exacerbate experimental autoimmune encephalomyelitis in HLA-DR3-transgenic mice. J Immunol (2009) 182(8):5131-9. doi:10.4049/jimmunol.0803918

45. Yamamoto Y, Mizuno R, Nishimura T, Ogawa Y, Yoshikawa H, Fujimura H, et al. Cloning and expression of myelin-associated oligodendrocytic basic protein. A novel basic protein constituting the central nervous system myelin. J Biol Chem (1994) 269(50):31725-30.

46. Schaeren-Wiemers N, Schaefer C, Valenzuela DM, Yancopoulos GD, Schwab ME. Identification of new oligodendrocyte- and myelin-specific genes by a differential screening approach. J Neurochem (1995) 65(1):10-22. doi:10.1046/j. 1471-4159.1995.65010010.x

47. de Rosbo NK, Kaye JF, Eisenstein M, Mendel I, Hoeftberger R, Lassmann H, et al. The myelin-associated oligodendrocytic basic protein region MOBP1536 encompasses the immunodominant major encephalitogenic epitope(s) for SJL/J mice and predicted epitope(s) for multiple sclerosis-associated HLADRB1¹501. J Immunol (2004) 173(2):1426-35. doi:10.4049/jimmunol.173.2. 1426

48. Holz A, Bielekova B, Martin R, Oldstone MB. Myelin-associated oligodendrocytic basic protein: identification of an encephalitogenic epitope and association with multiple sclerosis. J Immunol (2000) 164(2):1103-9. doi:10.4049/ jimmunol.164.2.1103

49. Greer JM, Csurhes PA, Cameron KD, McCombe PA, Good MF, Pender MP. Increased immunoreactivity to two overlapping peptides of myelin proteolipid protein in multiple sclerosis. Brain (1997) 120(Pt 8):1447-60. doi:10.1093/ brain/120.8.1447

50. Stromnes IM, Cerretti LM, Liggitt D, Harris RA, Goverman JM. Differential regulation of central nervous system autoimmunity by $\mathrm{T}(\mathrm{H}) 1$ and $\mathrm{T}(\mathrm{H}) 17$ cells. Nat Med (2008) 14(3):337-42. doi:10.1038/nm1715

51. Tjon JM, van Bergen J, Koning F. Celiac disease: how complicated can it get? Immunogenetics (2010) 62(10):641-51. doi:10.1007/s00251-010-0465-9

Conflict of Interest Statement: The authors declare that the research was conducted in the absence of any commercial or financial relationships that could be construed as a potential conflict of interest.

Received: 11 August 2014; paper pending published: 02 September 2014; accepted: 29 September 2014; published online: 16 October 2014.

Citation: Kaushansky $N$ and Ben-Nun A (2014) DQB1*06:02-associated pathogenic anti-myelin autoimmunity in multiple sclerosis-like disease: potential function of $\mathrm{DQB1}^{*} 06: 02$ as a disease-predisposing allele. Front. Oncol. 4:280. doi: 10.3389/fonc. 2014.00280

This article was submitted to Tumor Immunity, a section of the journal Frontiers in Oncology.

Copyright $(2014$ Kaushansky and Ben-Nun. This is an open-access article distributed under the terms of the Creative Commons Attribution License (CC BY). The use, distribution or reproduction in other forums is permitted, provided the original author(s) or licensor are credited and that the original publication in this journal is cited, in accordance with accepted academic practice. No use, distribution or reproduction is permitted which does not comply with these terms. 